\title{
Statistical analysis of cone penetration resistance of railway ballast
}

\author{
Gilles Saussine, Amine Dhemaied, Quentin Delforge and Selim Benfeddoul
}

SNCF Réseau - I\&P - LVE - CIR

\begin{abstract}
Dynamic penetrometer tests are widely used in geotechnical studies for soils characterization but their implementation tends to be difficult. The light penetrometer test is able to give information about a cone resistance useful in the field of geotechnics and recently validated as a parameter for the case of coarse granular materials. In order to characterize directly the railway ballast on track and sublayers of ballast, a huge test campaign has been carried out for more than 5 years in order to build up a database composed of 19,000 penetration tests including endoscopic video record on the French railway network. The main objective of this work is to give a first statistical analysis of cone resistance in the coarse granular layer which represents a major component of railway track: the ballast. The results show that the cone resistance $\left(\mathrm{q}_{\mathrm{d}}\right)$ increases with depth and presents strong variations corresponding to layers of different natures identified using the endoscopic records. In the first zone corresponding to the top $30 \mathrm{~cm},\left(\mathrm{q}_{\mathrm{d}}\right)$ increases linearly with a slope of around $1 \mathrm{MPa} / \mathrm{cm}$ for fresh ballast and fouled ballast. In the second zone below $30 \mathrm{~cm}$ deep, $\left(q_{d}\right)$ increases more slowly with a slope of around $0,3 \mathrm{MPa} / \mathrm{cm}$ and decreases below $50 \mathrm{~cm}$. These results show that there is no clear difference between fresh and fouled ballast. Hence, the $\left(\mathrm{q}_{\mathrm{d}}\right)$ sensitivity is important and increases with depth. The $\left(\mathrm{q}_{\mathrm{d}}\right)$ distribution for a set of tests does not follow a normal distribution. In the upper $30 \mathrm{~cm}$ layer of ballast of track, data statistical treatment shows that train load and speed do not have any significant impact on the $\left(\mathrm{q}_{\mathrm{d}}\right)$ distribution for clean ballast; they increase by $50 \%$ the average value of $\left(\mathrm{q}_{\mathrm{d}}\right)$ for fouled ballast and increase the thickness as well. Below the $30 \mathrm{~cm}$ upper layer, train load and speed have a clear impact on the $\left(\mathrm{q}_{\mathrm{d}}\right)$ distribution.
\end{abstract}

\section{Introduction}

The ballast layer is composed of coarse granular material and supports the loading of railway traffic. The design or track renewal are the most important operation in terms of cost. The characterization of the mechanical state is a fundamental work in order to optimize decision making $[1,9,12]$. The dynamic penetrometer test, known as Panda's test $[2,3,11]$, offers the opportunity to study changes in the stiffness by measuring the dynamic cone resistance $\left(\mathrm{q}_{\mathrm{d}}\right)$ at a given depth.

For more than 5 years, a huge campaign test has been realized on the French railway network using this technique. On the basis of strain energy measured at each hammer hit and the driving depth, the dynamic cone resistance is calculated. To this mechanical information is added visual information given by an endoscope camera. Thanks to the cone resistance values and the images, each layer can be identified accurately. This paper addresses some statistical analyses carried out on the database built from more than 19,000 penetration tests.

\section{Analyzed data}

The database has been constructed using Python programming language in order to examine statistical properties of cone resistance of railway layers based on different conditions.

\subsection{The cone resistance data set}

The database consists in several columns table where each line contains: cone resistance value at a given depth and several parameters related to this measure. The data set contains information on the characteristics of the railway where penetrometer test has been realized, which enables geographical, climatic factors, stratigraphy and thickness of identified layers by the endoscope, parameters related to railway type including speed and load capacity and identity of the survey. The Tab. 2.1 summarizes variables investigated in the study.

Tab. 2.1 Variables analyzed.

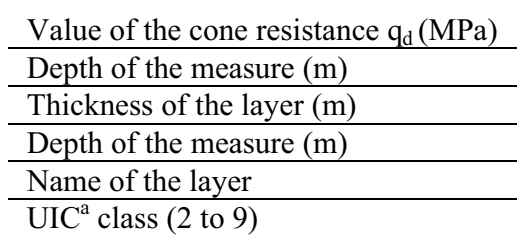

\footnotetext{
a It classifies railways in different groups based on their daily tonnage. The UIC class of the railway is an important factor which is discussed in more details in this article.
} 


\subsection{Filtering the data}

The penetrometer test is validated when cone resistance and layers identification from the ballast to the platform are both known [8]. The database is composed of numerous tests which are a combination of mechanical investigation and visual information from endoscopic test which allow to identify the nature of material for each measurements. In some case the endoscopic investigation are not possible because the sounding conditions are not successful $[5,6]$.

Therefore, the filtered data set used was reduced from 19,827 to 5,584 surveys, only $28 \%$ (Tab. 2.2) of the data is retained. The second step of our study will be to complete the missing data. A survey is defined in this paper as a sounding in railway track structure.

Tab. 2.2 Amount of raw data and cleaned data.

\begin{tabular}{|l|l|l|}
\hline & $\begin{array}{l}\text { Measures (value of cone } \\
\text { resistance at a given depth) }\end{array}$ & Surveys \\
\hline Initial database & $1,836,659$ & 19,827 \\
\hline Filtered database & 489,538 & 5,557 \\
\hline
\end{tabular}

Fig. 2.1 and Fig. 2.2 show the scatter of the cone resistance value $\left(q_{d}\right)$ versus the depth of the measure in the interlayer using the raw data and the cleaned data.

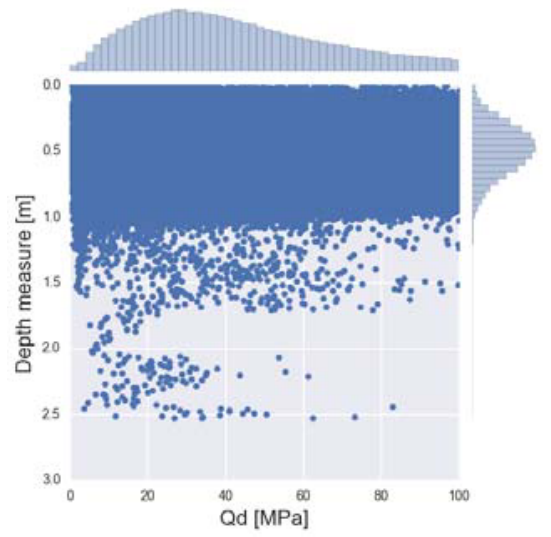

Fig. 2.1 Scatter plot of the depth versus the cone resistance in the interlayer using raw data.

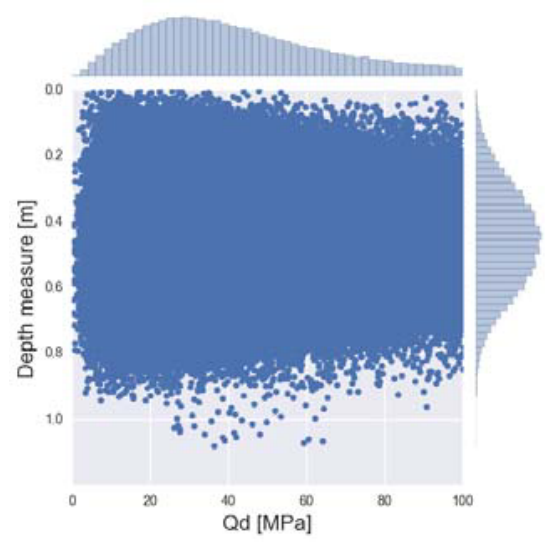

Fig. 2.2 Scatter plot of the depth versus the cone resistance in the interlayer using filtered data.

The interlayer $[7,1]$ originally identified between 0 and $2.5 \mathrm{~m}$ depth is now contained between 0.1 and $1.1 \mathrm{~m}$.
On those figures, zero corresponds to the under sleeper level.

The distribution of the filtered data is represented in a pie chart (Fig. 2.3). This gives us a good indication about line traffic distribution which is commonly called UIC group.

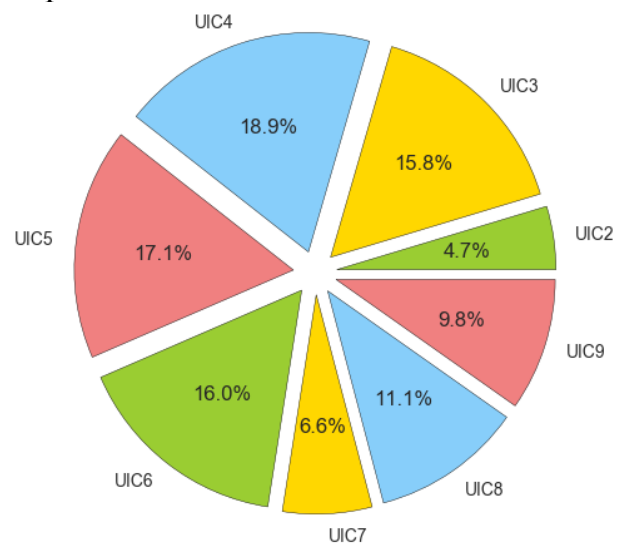

Fig. 2.3 Distribution of the filtered data by UIC groups.

The results obtained for the UIC groups 2, 7, 8 and 9 are less representative than those of the others groups (Fig. 2.3).

\section{Observations}

\subsection{Cone resistance variation with depth}

The first observation made on the filtered data concerns the variation of cone resistance with depth and the effect of the UIC group on this variation. Fig. 3.1 illustrates the variation of $\left(\mathrm{q}_{\mathrm{d}}\right)$ with depth for each UIC group. Cone resistance values are generated by averaging the data contained in $2 \mathrm{~cm}$ ranges.

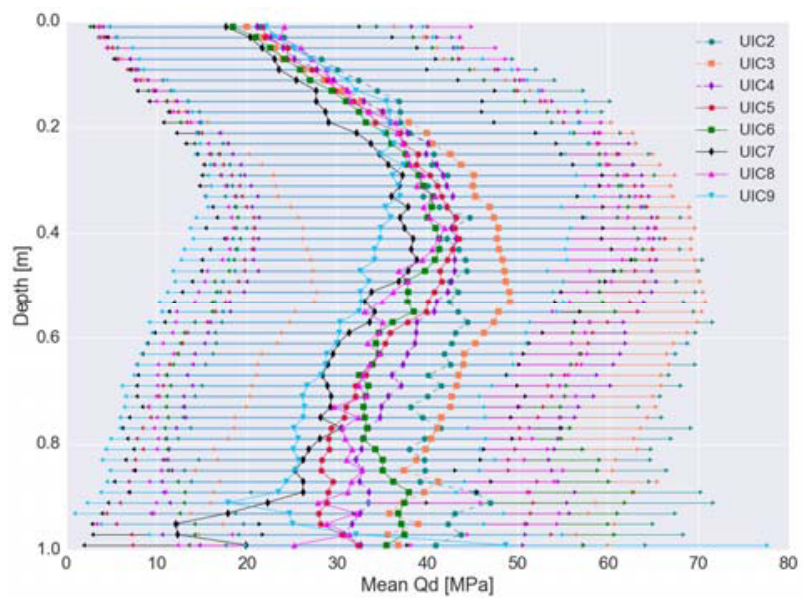

Fig. 3.1 (qd) variation with depth for four UIC groups.

We found that in the first zone corresponding to the first $30 \mathrm{~cm},\left(\mathrm{q}_{\mathrm{d}}\right)$ is increasing approximatively linearly with a slope of around $1 \mathrm{MPa} / \mathrm{cm}$ [2] and seems to be independent of the UIC group. Bellow this zone, the cone resistance presents strong variations. We also found that UIC group has an impact since the highest $\left(q_{d}\right)$ corresponds to the class of tonnage UIC3 (loading between 50,000 and 85,000 millions of tons) and lowest 
$\left(\mathrm{q}_{\mathrm{d}}\right)$ corresponds to UIC8 (loading to 1,500 millions of tons).

\subsection{Effect of the UIC class on cone resistance}

By plotting mean values of $\left(\mathrm{q}_{\mathrm{d}}\right)$ for each UIC group and for each layer (Fig. 3.2), we validate the observation made in the previous section. The cone resistance tends to decrease with the reduction of load capacity railway, except for the clean ballast.

Besides, the statistical treatment of the data shows that train load and speed do not have any significant impact on the distribution of $\left(\mathrm{q}_{\mathrm{d}}\right)$ for clean ballast. In the fouled ballast, average value of $\left(\mathrm{q}_{\mathrm{d}}\right)$ increase by about $50 \%$ for most of UIC groups (this increase is less significant for the groups 7 and 9). The density of fouled ballast is about more than 1.5 more important of clean ballast.

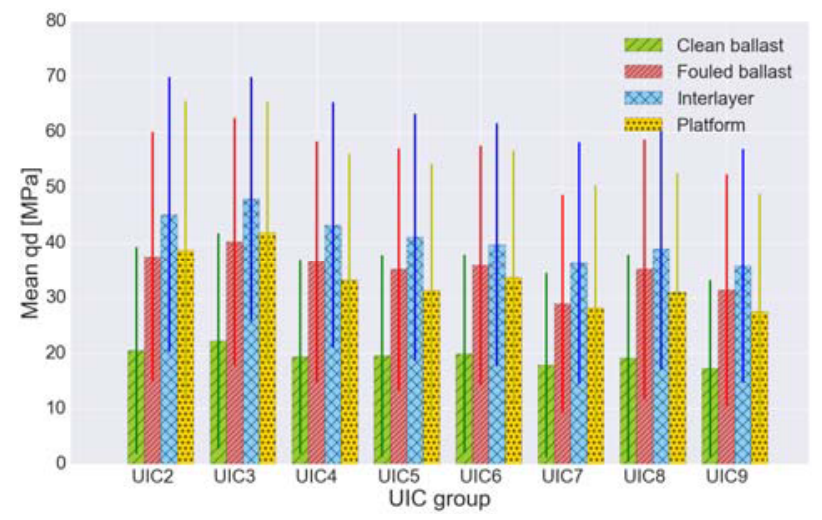

Fig. 3.2 Mean values of qd by UIC group and for each layer.

\subsection{Effect of the UIC class on layers thickness}

Fig. 3.3 illustrates that the thickness of ballast (clean and fouled) is linked with the UIC group in that a trend is discernible on the boxplots: for groups above UIC6, the thickness of ballast is less important which can be explained by the mean number of years from the last track renewal.

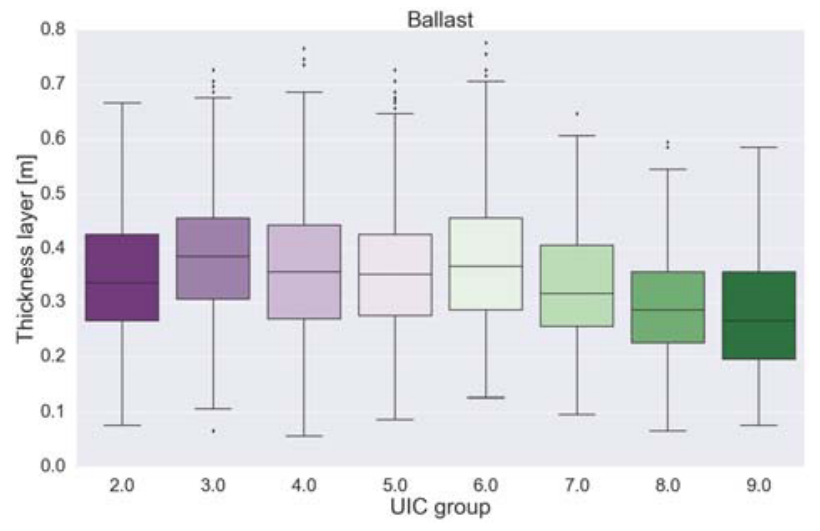

Fig. 3.3 Effect of the UIC group on the ballast thickness.

In the same way as the dynamic cone resistance, average value of the thickness layer is plotted for each UIC group (Fig. 3.4). The interlayer thickness [10,1] is independent of the UIC group. However, the clean ballast thickness declines from the UIC group 6 .

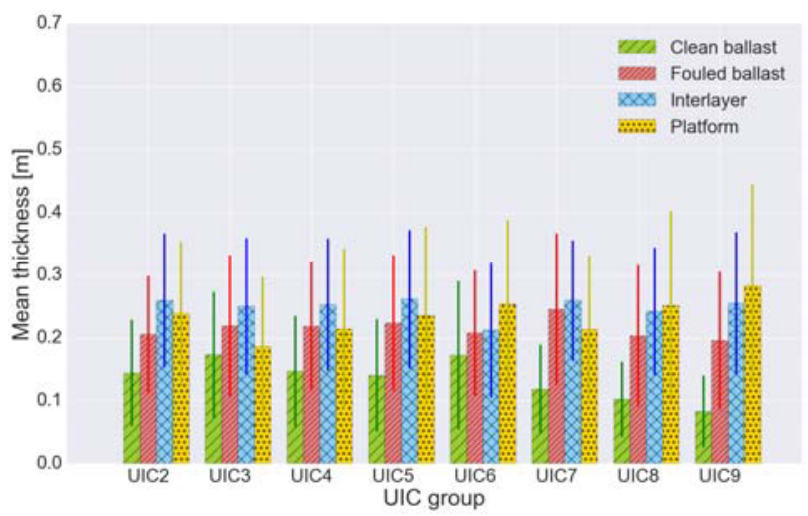

Fig. 3.4 Mean values of thickness by UIC group and for each layer.

\subsection{Thickness layers effect on cone resistance}

Fig. 3.5 illustrates the correlation between the fouled ballast and interlayer thicknesses and the cone resistance value for UIC groups we have the greater portion of data (e.g. groups 3, 4, 5 and 6). We found that no specific correlation can be observed.

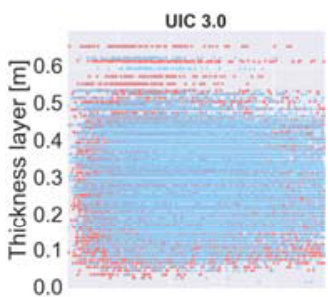

UIC 5.0

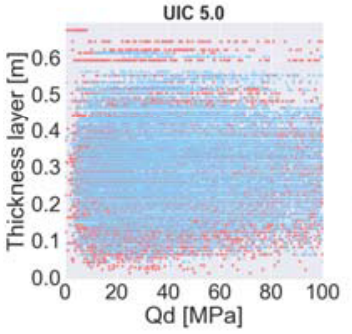

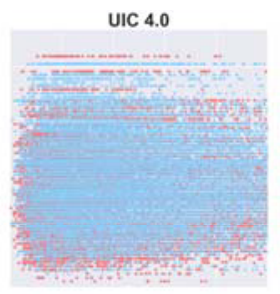

UIC 6.0

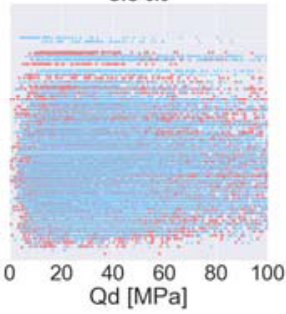

Fig. 3.5 Scatter plot of the fouled ballast and interlayer thickness versus the cone resistance value by UIC group

\subsection{Influence of the penetrometer test location on the railway}

We observe the impact of the location of the penetrometer test considering two areas: the first one located on the central position between the rails and the second located under the rail and called "outside" for the following of the study. We figure out the effect of the location test on the cone resistance and the thickness of clean and fouled ballast layers. Fig. 3.6 illustrates a classical feature: fouled ballast layer thickness is more important under the sleeper and rail which support the railway traffic. 

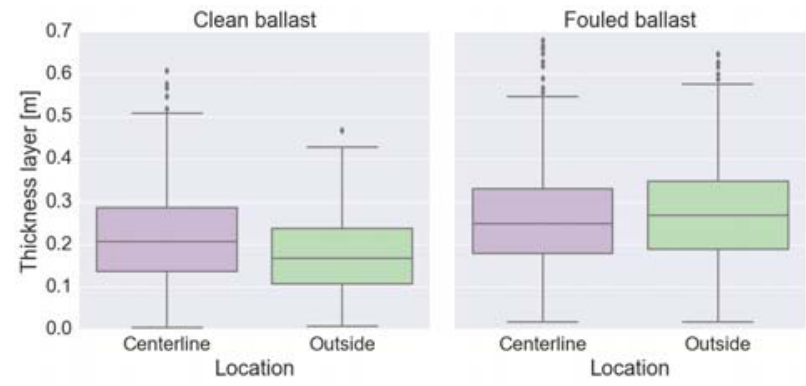

Fig. 3.6 Effect of the test location on the thicknesses of clean and fouled ballasts
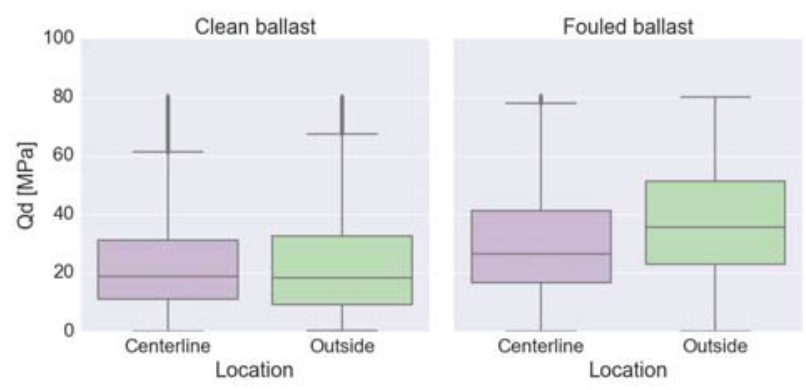

Fig. 3.7 Effect of the test location on the cone resistance for clean and fouled ballasts

On Fig. 3.7, we notice that statically the fouled ballast layer is important in centerline which is an important results that influence the track renewal operation in terms of fresh ballast add or effort for recycling existing material [7]

\section{Conclusion}

This paper has quantified the statistical properties of cone resistance of railway layers which is an important result for decision making of railway track renewal. This statistical study allows to evaluate the influence of thickness or traffic loading. The initial study carried on the filtered data reveals that cone resistance presents strong variations below $30 \mathrm{~cm}$ deep and depends on the UIC class. Above this depth, in the clean ballast, $\left(\mathrm{q}_{\mathrm{d}}\right)$ is independent of the UIC group. The most important dependence observed between the UIC group and the thickness layers concerns the clean ballast.

This preliminary analyses gives the opportunity to predict the track settlement by using a model based on the Chicago's density relaxation law [8] or the cone penetrometer improvements. The theoretical model was tested on experimental data and a prediction of settlement evolution with an error less than $10 \%$ was achieved.

\section{References}

1. SNCF - direction de l'ingénierie, "IN4103 : directive d'études voie, version $\mathrm{N}^{\circ} 3$ " du $(13 / 07 / 2011)$
2. R. Gourvès, "Le PANDA - pénétromètre dynamique léger à énergie variable", LERMES CUST, Université Blaise Pascal Clermont-Ferrand, (1991)

3. AFNOR, "NF P94-105 : Sols : reconnaissance et essais - Contrôle de la qualité du compactage Méthode au pénétromètre dynamique à énergie variable - Principe et méthode d'étalonnage du pénétromètre - Exploitation des résultats Interprétation", (Avril 2012)

4. P. Breul, R. Gourvès, Y. Haddani., "Géoendoscopie: caractérisation des géomatériaux par traitement et analyse d'images", revue française de génie civil, (2002)

5. Y. Haddani, "Caractérisation et classification des milieux granulaires par géoendoscopie", université Blaise Pascal, (2004)

6. Y. Haddani , G. Saussine, P. Breul, M.A Benz Navarrete, R. Gourvès, "Railway track stiffness and bearing capacity valuation thanks to panda and geoendoscopy tests", Georail, (2011)

7. P. Breul, R. Gourvès, A. Robinet, C. Bacconnet, "Assessment of the railway structures using an integrating testing and diagnosis methodology", Geotechnical and Geophysical Site Characterization, (2008)

8. G. Saussine, J.C. Quezada, P. Breul, F. Radjai, "Railway Ballast Settlement: A New Predictive Model", in J. Pombo, (Editor), "Proceedings of the Second International Conference on Railway Technology: Research, Development and Maintenance", Civil-Comp Press, Stirlingshire, UK, Paper 121, (2014). doi:10.4203/ccp.104.121

9. ASTM 6951, "Standard Test Method for Use of the Dynamic Cone Penetrometer in Shallow Pavement Applications", (2015)

10. N. Calon , M. Chanson., S. Nebieriedze, A. Robinet, "Auscultation des plates-formes ferroviaires par méthodes georadr et panda", Georail (2011) International symposium

11. Breul, P., Benz, M., Gourvès, R. \& Saussine, G. Penetration test modeling in a coarse granular medium. Paper presented at Powders and grains 2009: Proceedings of the 6th international conference on micromechanics of granular media. Golden, Colorado. AIP Conference Proceedings. (2009)

12. M.A. Benz-Navarrete, E. Escobar, Y. Haddani, R. Gourves, S. Costa D'Aguiar, N. Calon, "Determination of Soil Dynamic Parameters by the Panda 3®: Railways Platform Case", in J. Pombo, (Editor), "Proceedings of the Second International Conference on Railway Technology: Research, Development and Maintenance", Civil-Comp Press, Stirlingshire, UK, Paper 56, (2014). doi:10.4203/ccp.104.56 